\title{
Performance Evaluation of an Ironmaking System with Environmental Costs
}

\author{
Huimin Liu $(\mathbb{D})$ and Qiqiang Li $(\mathbb{D}$ \\ The School of Control Science and Engineering, Shandong University, Jinan 250061, China \\ Correspondence should be addressed to Qiqiang Li; qqli@sdu.edu.cn
}

Received 29 July 2020; Revised 16 September 2020; Accepted 30 September 2020; Published 23 October 2020

Academic Editor: Qiang Chen

Copyright (C) 2020 Huimin Liu and Qiqiang Li. This is an open access article distributed under the Creative Commons Attribution License, which permits unrestricted use, distribution, and reproduction in any medium, provided the original work is properly cited.

\begin{abstract}
This paper proposes an exergoeconomic analysis method that considers environmental costs to make up for the lack of description of environmental costs in the traditional matrix model exergoeconomic analysis method. This method tracks the formation process of the product cost through life cycle and makes a useful exploration for revealing the true cost of the system product. According to actual needs, the principles for the construction of environmental emissions of products are proposed, and a detailed exergoeconomic analysis model is established by taking the iron smelting system as an example. Through calculation and analysis, the formation process and change rule of unit exergoeconomic cost of products in the system are revealed. Especially, considering the exergoeconomic cost of carbon emissions, the results show that the three most influential substances are sinter, coke, and pellets. When carbon dioxide emissions are considered, the total cost will increase by $165.3 \mathrm{CNY} / \mathrm{t}$ iron, and unit exergoeconomic cost gradually increases with the progress of the production process.
\end{abstract}

\section{Introduction}

At present, energy conservation and environmental protection issues have attracted much attention. The rapid development of China's industries has a great impact on the environment. The rapid development of industries consumes a lot of energy, and the carbon dioxide produced cannot be ignored [1]. The carbon dioxide in the steel industry accounts for $10 \%$ of the domestic total. In addition to the power and construction industries, the steel industry is the third largest industry for carbon dioxide emissions [2]. The concept of green development is more conducive to promoting industries to save resources and protect the environment [3-6]. Some scholars have conducted research about $\mathrm{CO}_{2}$ emission reduction measures [7-9], emission reduction costs $[10,11]$, and emission forecast in the steel industry. These studies have a profound impact on energy conservation and environmental protection in the steel industry, but most of them only focus on industrial emissions, and few specific studies focus on enterprise emissions. Therefore, how to reasonably evaluate the carbon emissions of the ironmaking systems is very meaningful to the product cost of the ironmaking systems. For energy conservation, some scholars conduct research from the perspective of exergy.

On the basis of the laws of thermodynamics, some scholars tried to use the exergy method [12-16] to study how to reduce the energy consumption and environmental impact of blast furnace ironmaking [17-23]. Szargut [24] used exergy in metallurgy earlier. Akiyama and Yagi [17] used the same method to study the energy use of blast furnaces. Ziebik and Stanek [19] improved the existing mechanism model on the basis of experiments and proposed a calculation method for blast furnace performance. They not only obtained the main parameters that affect the performance of the blast furnace but also pointed out that the exergy loss in the compression and waste heat process is the largest. Ziebik and Stanek [20] analysed by using energy and exergy and found that the amount of coke seriously affects blast furnace performance. Zhang [21] also analysed the performance of the blast furnace through the exergy method and found the reason for the low efficiency of the blast furnace. In addition, 
the efficiency can be improved by increasing the temperature and coal ratio of the blast furnace. Guo et al. [22] established a blast furnace exergy analysis model with coke oven injection and analysed its influence. In addition, Wang [23] showed that after considering the injection of coke oven gas, the exergy and thermodynamic performance improved significantly.

Although the exergy method can reflect the level and reason of the thermal efficiency of the system, it still has shortcomings in reflecting the internal costs of the system. The exergoeconomic analysis combined with energy and economy can reflect internal costs and make up for the deficiency of the exergy method [25]. In addition, the research of Blumberg et al. [26] showed that it is very beneficial to reduce the cost of multiproduct systems. Uysal et al. [27] used the exergoeconomic analysis method to analyse coalfired boilers. Wang et al. [28] conducted an exergoeconomic analysis to evaluate a cogeneration. Hofmann et al. [29] applied the exergoeconomic method to the CHP plant and carried out a useful exploration of the internal cost of the CHP plant.

Environmental impact analysis involves many factors. Some scholars first simplified the environmental impact to $\mathrm{CO}_{2}$ emissions and then used the exergy economic method to conduct research and obtained some results in the model [29, 30]. Holmberg et al. [29] studied not only the fuel cost distribution of cogeneration plants but also the carbon dioxide emissions of cogeneration and used the exergy method and market method for analysis and comparison.

The above research analysed the performance of the ironmaking system from the perspective of exergy or exergoeconomics, but the effect of $\mathrm{CO}_{2}$ emissions on the exergoeconomics of the ironmaking system is not taken into account. This part of the cost cannot be ignored. This article consists of five sections. Section 2 shows a general description of the ironmaking system and its main input and output materials. Section 3 establishes the exergoeconomic and the environmental cost model considering $\mathrm{CO}_{2}$ emissions. The performance evaluation results and the main impact substances are shown in Section 4. Conclusions are given in Section 5.

\section{System Description}

Figure 1 shows a schematic diagram of the ironmaking process, which defines the research boundary. Steel manufacturing involves sintering, coking, ironmaking, steelmaking, and rolling. The energy sources of the sintering process are mainly fuel and electricity. During sintering, various iron-containing raw materials are mixed with appropriate amount of fuel and solvent and an appropriate amount of water is added to cause a series of physical and chemical reactions to produce sintered ore. Controlling the ignition temperature, changing the material state, and optimizing the proportion of the mixture can reduce the energy consumption of the sintering process $[10,31]$. In the coking process, coal is subjected to high-temperature dry distillation to produce coke, and other chemical products such as coke oven gas and tar are recovered. In the ironmaking process, sintered ore, coke, and solvent are charged from the top of the furnace, hot air is blown in from the tuyere at the lower part of the blast furnace, and fuels such as oil, coal, or natural gas are injected. Oxygen burns with coke at high temperatures. Carbon monoxide is produced and flows upward through the blast furnace. Carbon and carbon monoxide reduce the iron ore to obtain iron. The gas produced in the blast furnace will be recycled and reused in processes such as coking and rolling. The molten iron is sent to the converter, and high-pressure and high-purity oxygen is injected into the furnace. The oxygen reacts with iron to remove the carbon in the iron to obtain crude steel. Converter gas is also recycled and reused [32]. Herein, this article focuses on the ironmaking process, and the main equipment and materials are described in Figure 1.

Because there are a lot of physical and chemical reactions during ironmaking, in order to obtain better results, some reasonable assumptions need to be made when establishing an analysis model as follows. (1) The physical and chemical reactions in the whole process are in equilibrium. (2) The substances involved in the reaction are assumed to be ideal mixtures. (3) The temperature of the raw materials entering the blast furnace is assumed to be the ambient temperature, which is $298 \mathrm{~K}$, and the remaining parameters are determined by the actual production situation.

\section{Methods}

3.1. Exergoeconomic Analysis. Exergy analysis should be completed first, which is necessary for both new analyses. This is the general expression of exergy. The exergy method includes the first and second laws of thermodynamics. The first law and the second law of thermodynamics make up the exergy methods. This is a great evaluation method. The general exergy balance is shown as follows:

$$
\begin{aligned}
& \sum E x_{\text {in }}=\sum E x_{\text {out }}+\sum E x_{\text {dest }}, \\
& \sum E x_{\text {in }}=\left[E x_{\text {out,useful }}+E x_{\text {loss }}\right]+\sum E x_{\text {dest }},
\end{aligned}
$$

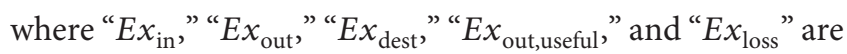
exergy input, exergy output, exergy destruction, useful exergy output, and exergy loss, respectively.

Exergy analysis was described in detail in literature [16].

The mass balance is shown in the following formula:

$$
\sum m_{\text {in }}=\sum m_{\text {out }} \text {. }
$$

The general energy balance is shown in the following formula:

$$
Q_{\text {net,in }}-W_{\text {net,out }}=\sum m_{\text {out }} h_{\text {out }}-\sum m_{\text {in }} h_{\text {in }}
$$

where $Q$ is the rate of heat transfer, $W$ is the rate of work, $m$ is the mass flow rate, and $h$ is the enthalpy.

The efficiency of the first law of thermodynamics is given as follows:

$$
\eta_{1}=\frac{\sum E_{\mathrm{out}}}{\sum E_{\mathrm{in}}}
$$




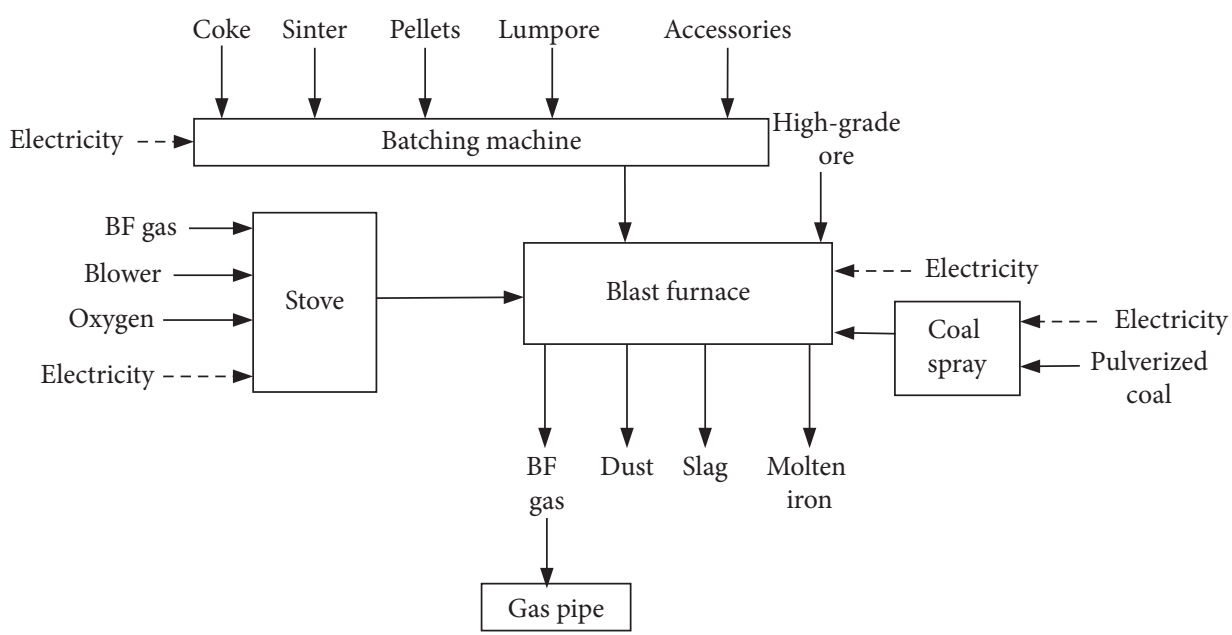

Figure 1: Simplified scheme of iron and steel production routes and processes.

The second law of thermodynamics and the general exergy balance are expressed as follows:

$$
\begin{gathered}
\sum E x_{\text {in }}-\sum E x_{\text {out }}=\sum E x_{\text {dest }}, \\
\sum\left(1-\frac{T_{0}}{T_{P}}\right) Q_{P}-W_{\text {net,out }}+\sum m_{\text {in }} \phi_{\text {in }} \\
-\sum m_{\text {out }} \phi_{\text {out }}=\sum E x_{\text {dest }},
\end{gathered}
$$

where $Q$ is the rate of heat transfer through the boundary at temperature $T_{P}$ and the subscript zero indicates properties at dead state of $P_{0}$ and $T_{0}$. Equation (8) shows the flow exergy with negligible kinetic and potential energies:

$$
\varphi=\left(h-h_{0}\right)-T_{0}\left(S-S_{0}\right) .
$$

The exergy destroyed is expressed as follows:

$$
E x_{\text {dest }}=T_{0} S_{\text {gen }},
$$

where $S_{\text {gen }}$ is the ratio of entropy generation.

The efficiency expression of the second law of thermodynamics is shown in the following formula:

$$
\eta_{\Pi}=\frac{\sum E x_{\text {out }}}{\sum E x_{\text {in }}} .
$$

System designers or operators obtain energy efficiency through energy analysis and obtain system economic distribution through economic analysis, while exergy economic analysis can obtain energy expenditure, which is not available through energy and economic analysis. This is very important for system design and operation evaluation. It is convenient to reveal how to use resources more efficiently to save resources.

When performing economic analysis of the system, the expenditure of the entire system needs to be provided. Fuel cost, operation, and maintenance are all basic data, while during the whole operation period, the cost of equipment is changing. Therefore, the equivalent annual value method is generally used in the economic analysis of the system [26].

$$
\begin{aligned}
A & =\operatorname{CRF} \sum_{m=1}^{n} P_{m}, \\
P_{m} & =C_{m} \frac{1}{(1+j)^{m}}, \\
\mathrm{CRF} & =\frac{i(1+i)^{n}}{(1+i)^{n}-1},
\end{aligned}
$$

where $A$ is the average cost, $P_{m}$ is the present value of investment, $j$ is the depreciation rate, CRF is the capital recovery factor, $n$ is the investment period, and $i$ is the interest rate.

Evaluating the expenditure of the flow in the factory is helpful for understanding the cost formation process from the input of resources to the final product [33]. There are three steps in this method. The first step is to identify exergy. In the second step, the fuel and product of equipment in the system are to be defined. The third step is to configure the cost balance, as shown below.

\subsection{Definition of Exergy Flow.}

$$
\begin{aligned}
C_{i} & =c_{i} E x_{i}=c_{i}\left(m_{i} \varphi_{i}\right), \\
C_{e} & =c_{e} E x_{e}=c_{e}\left(m_{e} \varphi_{e}\right), \\
C_{w} & =c_{w} E x_{w}, \\
C_{q} & =c_{q} E x_{q} .
\end{aligned}
$$

For a unit that consumes power and radiates heat outward, its balance is shown in the following equation [34]:

$$
\sum_{i} c_{i} E x_{i}+c_{w} E x_{w}+Z_{K}=\sum_{e} c_{e} E x_{e}+c_{q} E x_{q} .
$$

3.3. Exergoeconomic Analysis with $\mathrm{CO}_{2}$. The production process of iron is a typical chemical process of iron and coal. The input of carbon, that is, the source of $\mathrm{CO}_{2}$ emissions, mainly comes from the burning of fuels and the 
decomposition of limestone. Assume that all carbon-containing raw materials and fuels are eventually emitted in the form of carbon dioxide. Other forms of emissions, such as $\mathrm{CO}_{2}$ and alkanes, are eventually oxidized to carbon dioxide, so all carbon released can be counted as carbon dioxide emissions. If the sintering, coking, and blast furnace ironmaking processes are used as a balance system, then the carbon input of all raw materials is identified and defined, and the carbon dioxide emissions of the fixed carbon equivalent within the boundary and the carbon emissions of all products are calculated. Figure 2 shows the carbon emission model of the ironmaking system. The carbon input of the model includes some carbon energy, substances (such as solvents), and carbon emissions, including carbon dioxide emissions from the process and fixed carbon contained in products and secondary products.

We calculate emission factors according to China's "General Principles of Comprehensive Energy Calculation" and strive to be consistent with China's actual carbon emissions. The carbon emission factors are defined as follows:

$$
E F=Q \times C
$$

where $Q$ is the calorific value of the material or product, $G J(\mathrm{t})$ or $\mathrm{G} J\left(\mathrm{~m}^{3}\right)$, and $C$ is the conversion rate, $t_{\mathrm{CO}_{2}}(G J)$.

Formulas for calculating carbon dioxide emissions for each process and ironmaking system are given as follows:

$$
\begin{aligned}
E_{\mathrm{CO}_{2}}= & \left(\sum_{i=1}^{M} M_{i} \times E F_{i}+\sum_{i=M+1}^{m} M_{i} \times E F_{i}^{\prime}\right) \\
& -\sum_{j=1}^{n} D_{j} \times E F_{j},
\end{aligned}
$$

where $E_{\mathrm{CO}_{2}}$ is the total carbon dioxide emissions, $t ; M_{i}$ is the consumption of carbonaceous materials; $D_{j}$ is the output of products and secondary products; $E F_{i}$ is the direct carbon emission factor of carbon-containing raw fuel; $E F_{i}^{\prime}$ is indirect Carbon; and $E F_{j}$ is the carbon offset of the product (byproduct).

Combine the above two formulas to obtain

$$
\begin{aligned}
E_{\mathrm{CO}_{2}}= & \left(\sum_{i=1}^{M} M_{i} \times C_{M i} \times Q_{M i}+\sum_{i=M+1}^{m} M_{i} \times C_{M i}^{\prime} \times Q_{M i}^{\prime}\right) \\
& -\sum_{j=1}^{n} D_{j} \times C_{D j} \times Q_{D j} .
\end{aligned}
$$

where $C_{M i}, C_{M i}^{\prime}$, and $C_{D j}$ are the conversion factors input carbonaceous materials, noncarbon materials, and output products (by-products), respectively; $Q_{M i}, Q_{M i}^{\prime}$, and $Q_{D j}$ are the calorific value of the conversion factors input carbonaceous materials, noncarbon materials, and output products (by-products).

The exergy method can evaluate the environmental factors in economic analysis because it can track the process of energy input to consumption [35]. EXENEC analysis uses the parameter " $\mathrm{C}_{\mathrm{CO}_{2}}$ " (\$/time) for determination. This parameter gives the price information of $\mathrm{CO}_{2}$ emissions in a given time as follows:

$$
\mathrm{C}_{\mathrm{ECO}_{2}}={ }^{\mathrm{E}} \mathrm{CO}_{2} \times \mathrm{C}_{\mathrm{CO}_{2}} \text {. }
$$

\section{Results and Discussion}

4.1. Exergoeconomic Analysis of the Blast Furnace. Taking a certain ironmaking system as the research target and using the exergoeconomic model established above, we calculate and analyse the exergy economic cost of the blast furnace.

The internal exergy of the system is divided into 18 streams, of which 12 are imported from the outside and 6 are output to the system. The equations are established through the exergoeconomic balance and solved by MATLAB to obtain the cost of each stream as shown in Table 1 .

Exergoeconomic cost analysis shows that sinter has the largest influence, followed by coke and pellet, which are the main components of ironmaking product cost. Among them, sinter accounts for $46.15 \%$ of the input cost, coke accounts for $25.74 \%$, and pellet accounts for $17.56 \%$.

4.2. Exergoeconomic Analysis with $\mathrm{CO}_{2}$ of the Blast Furnace. The model uses the raw fuel consumed to produce one ton of molten iron as the unit of measurement and determines the consumption and heat income and expenditure of each material on the basis of the material and energy balance. The main chemical components of the raw fuel used in the calculation are described in Tables 2 and 3. The constitution of coke oven gas is presented in Table 4 [35].

Regarding the environmental cost of the system, in order to simplify, we only consider the $\mathrm{CO}_{2}$ emissions. According to the previous model, the content and calorific value of carbon-containing raw materials and non-carbon-containing raw materials are calculated. At present, carbon dioxide billing is still under discussion. We assume that carbon dioxide is $140 \mathrm{CNY} / \mathrm{t}$ [36]. According to the above equation, the unit environmental cost of each stream of the system is calculated for the design of the ironmaking system, and the results are listed in Table 5.

Exergoeconomic analysis and exergoeconomic analysis considering carbon dioxide emissions are applied to an ironmaking system. The results of exergoeconomic analysis that does not consider $\mathrm{CO}_{2}$ and exergoeconomic analysis considering carbon dioxide emissions are described in $\mathrm{Ta}-$ bles 1 and 5. At the same time, the comparison results of two different analysis methods for the ironmaking system are shown in Figure 3. The highest exergoeconomic cost is sintered ore, which is $306.95 \mathrm{CNY}$, followed by coke, which is $449.86 \mathrm{CNY}$, and the third influence is pellets, which is 306.95 CNY. When carbon dioxide emissions are considered, the exergoeconomic costs of each stream have changed as shown in Figure 3. The major changes are coke, pulverized coal, and electricity. The thermal economic cost of coke was 535.96 CNY, an increase of 87.1 CNY, followed by coal powder, which increased by $46.284 \mathrm{CNY}$, and finally, electricity cost increased by about $28 \mathrm{CNY}$. 


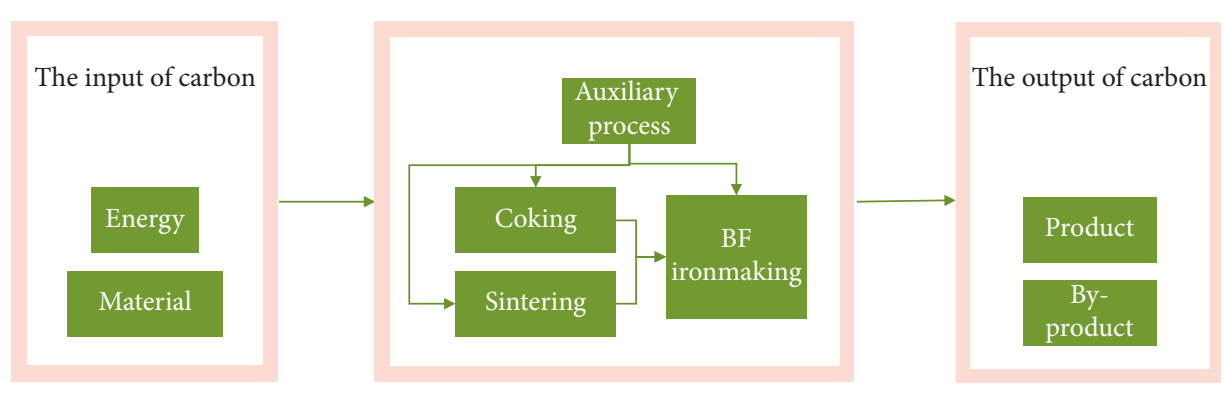

Figure 2: The boundary of the carbon emission model of the ironmaking system.

TABLE 1: Exergoeconomic cost of the ironmaking system.

\begin{tabular}{lcccc}
\hline Fuel (CNY/t molten iron) & & & & Product \\
Item & Cost & $\%$ & Item & Cost \\
\hline Pellets & 306.95 & 17.56 & Molten iron & 1508.83 \\
Sinter & 806.5 & 46.15 & BF gas & 24.84 \\
Coke & 449.86 & 25.74 & Slag & 209.33 \\
Lump ore & 14.46 & 0.83 & Scrap iron & 3.6 \\
Oxygen & 11.28 & 0.64 & Residual heat water & 1.42 \\
Pulverized coal & 81.9 & 4.69 & TRT electricity & 0.25 \\
BF gas & 10.9 & 0.63 & Total & 0.8 \\
Coke oven gas & 3.2 & 0.18 & & 0.014 \\
Low-pressure steam & 2.31 & 0.13 & & 0.046 \\
Nitrogen & 6.77 & 0.39 & & 100 \\
Electricity & 17.9 & 1.02 & & \\
Industrial water & 35.62 & 2.04 & & \\
Total & 1747.65 & 100 & & \\
\hline
\end{tabular}

TABLE 2: Main chemical composition of raw materials.

\begin{tabular}{lccccccccc}
\hline Item & $\mathrm{TFe}$ & $\mathrm{Fe}_{2} \mathrm{O}_{3}$ & $\mathrm{FeO}$ & $\mathrm{SiO}_{2}$ & $\mathrm{CaO}$ & $\mathrm{MgO}$ & $\mathrm{Al}_{2} \mathrm{O}_{3}$ & $\mathrm{MnO}$ & $\mathrm{S}$ \\
\hline Sinter & 58.3 & 17.354 & 6.93 & 5.86 & 7.74 & 1.53 & 1.94 & 0.34 & 0.0055 \\
Pellets & 64.13 & 26.815 & 0.64 & 3.81 & 3.4 & 1.2 & 0 & 0 & 0.005 \\
\hline
\end{tabular}

TABLE 3: Main chemical composition of fuel.

\begin{tabular}{|c|c|c|c|c|c|c|c|c|c|c|c|c|c|}
\hline \multirow{2}{*}{ Item } & \multirow{2}{*}{$\mathrm{C}$} & \multicolumn{5}{|c|}{ Volatile } & \multicolumn{6}{|c|}{ Ash } & \multirow[t]{2}{*}{$\mathrm{S}_{\mathrm{ORC}}$} \\
\hline & & $\mathrm{CO}_{2}$ & $\mathrm{CO}$ & $\mathrm{H}_{2}$ & $\mathrm{CH}_{4}$ & $\mathrm{~N}_{2}$ & $\mathrm{SiO}_{2}$ & $\mathrm{CaO}$ & $\mathrm{MgO}$ & $\mathrm{Al}_{2} \mathrm{O}_{3}$ & S & $P$ & \\
\hline Coke & 85.76 & 0.434 & 0.459 & 0.074 & 0.05 & 0.223 & 6.355 & 0.636 & 0.508 & 5.084 & 0.057 & 0.009 & 0.58 \\
\hline Pulverized coal & 83.55 & 1.763 & 0.993 & 1.347 & 0.689 & 4.660 & 0.460 & 0.370 & 3.720 & 0.041 & 0.006 & 0.56 & \\
\hline
\end{tabular}

TABLE 4: Coke oven gas composition.

\begin{tabular}{lcccccc}
\hline Constitute & $\mathrm{H}_{2}$ & $\mathrm{CH}_{4}$ & $\mathrm{CO}$ & $\mathrm{CO}_{2}$ & $\mathrm{~N}_{2}$ & $\mathrm{C}_{\mathrm{n}} \mathrm{H}_{\mathrm{m}}$ \\
\hline$\%$ & 57.4 & 26.4 & 8.60 & 2.00 & 3.60 & 2.00 \\
\hline
\end{tabular}

After quantitative analysis, the proportion of flow cost in the total cost is shown in Figure 4(a). To simplify the consideration of the environment, $\mathrm{CO}_{2}$ is only considered as a pollutant, and its impact on the total cost ratio is not obvious. However, if we take the difference in the share of flow cost per share, as shown in Figure 4(b), it can be seen that the impact of carbon dioxide on the cost is different. Considering the carbon dioxide emissions, the total production cost of the ironmaking system becomes higher and the expenditure of links with a large impact of carbon dioxide will also increase, such as $2.33 \%$ increase in coke and $2.11 \%$ increase in coal powder.

The cost of the part with less carbon dioxide impact decreases accordingly, such as pellets reduced by $1.28 \%$ and sintered ore reduced by $4 \%$. It is worth noting that although the cost of electricity has increased, the increase in the proportion of its cost is negative $(0.17 \%)$. This is because the increase rate of electricity cost is less than the increase rate of total cost. 
TABLE 5: Exergoeconomic cost with $\mathrm{CO}_{2}$ of the ironmaking system.

\begin{tabular}{lcccc}
\hline Fuel (CNY/t molten iron) & & & & \multicolumn{2}{c}{ Product } \\
Item & Cost & $\%$ & Item & Cost \\
\hline Pellets & 306.95 & 16.05 & Molten iron & 1674.134 \\
Sinter & 806.5 & 42.16 & BF gas & 24.84 \\
Coke & 536.96 & 28.08 & Slag & 209.33 \\
Lump ore & 14.46 & 0.75 & Scrap iron & 3.6 \\
Oxygen & 11.28 & 0.59 & Residual heat water & 0.25 \\
Pulverized coal & 128.184 & 6.7 & TRT electricity & 0.8 \\
BF gas & 13.84 & 0.73 & Total & 0.19 \\
Coke oven gas & 4.18 & 0.21 & & 0.01 \\
Low-pressure steam & 2.31 & 0.12 & & 0.04 \\
Nitrogen & 6.77 & 0.35 & & 100 \\
Electricity & 17.9 & 2.4 & & \\
Industrial water & 35.62 & 1.86 & & \\
Total & 1912.954 & 100 & & \\
\hline
\end{tabular}

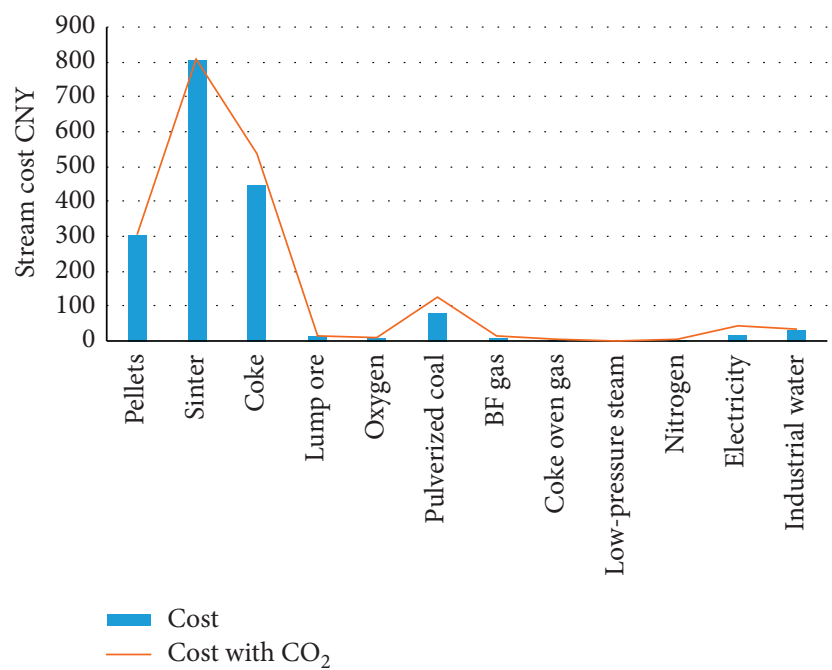

FIgURE 3: Cost of each stream.

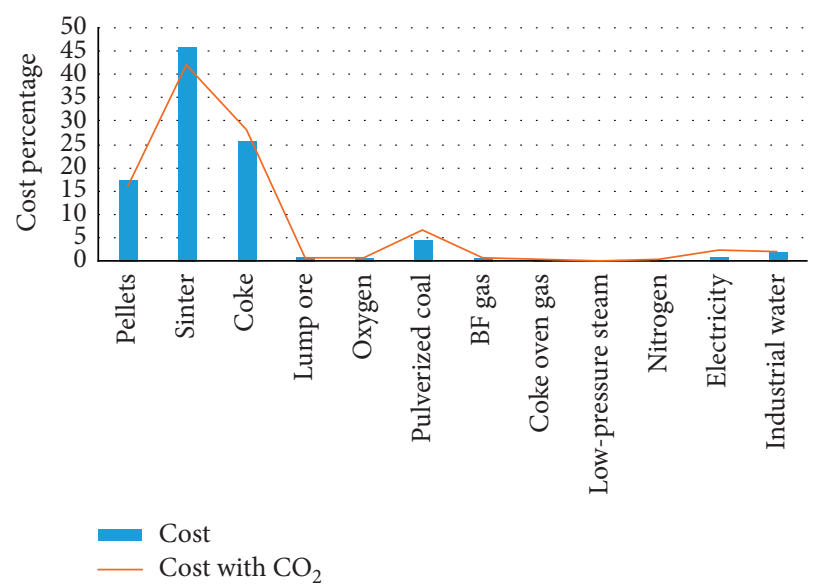

(a)

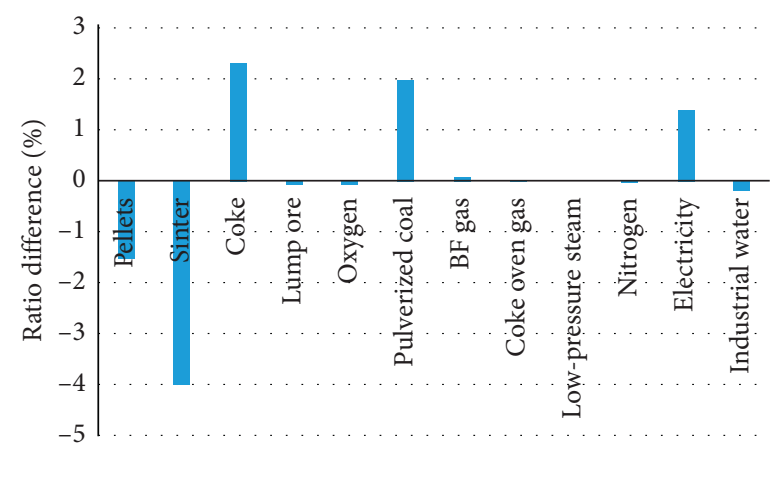

(b)

Figure 4: (a) Cost percentage of each stream. (b) Cost ratio difference. 
Through the above chart, we can intuitively obtain the exergoeconomic cost and exergoeconomic environmental cost in the production process of the ironmaking system, thereby revealing the exergoeconomic and environmental characteristics of the ironmaking system.

\section{Conclusions}

Based on the traditional thermoeconomic analysis, this paper considers the carbon emission of pollutants as an environmental factor and establishes an exergy economic model of the ironmaking system. The main conclusions are as follows:

(1) Through the exergoeconomic analysis of an actual ironmaking system, the unit exergoeconomic cost and unit environmental cost of its operation are analysed and calculated, the formation process of the cost is found, and the system is comprehensively analysed from thermodynamic, economic, and environmental factors.

(2) Based on the exergoeconomic analysis of the ironmaking system, the three highest exergoeconomic costs are sinter, coke, and pellets, accounting for $46.15 \%, 25.74 \%$, and $17.56 \%$, respectively. When considering carbon dioxide emissions, the exergoeconomic costs are $42.16 \%, 28.07 \%$, and $16.28 \%$, respectively. After considering carbon dioxide emissions, the total cost will increase by $165.3 \mathrm{CNY} / \mathrm{t}$ iron.

In this paper, the consideration of pollutant is simplified to carbon dioxide in the analysis of the ironmaking system, but the method in this paper can be extended to other environmental considerations and can also be applied to other energy systems. Although the way to consider carbon dioxide is still under discussion and the impact of other pollutants on the ecological environment is not included in the enterprise cost, they have caused a certain economic impact, which will be further considered in the future.

\section{Data Availability}

The data used to support the findings of this study are available from the corresponding author upon request.

\section{Conflicts of Interest}

The authors declare that they have no conflicts of interest regarding the publication of this paper.

\section{Acknowledgments}

This study was supported by the National Natural Science Foundation of China (61803174) and Shandong Provincial Natural Science Foundation (ZR2019BF024).

\section{References}

[1] H. Zhang, L. Dong, H. Li et al., "Investigation of the residual heat recovery and carbon emission mitigation potential in a
Chinese steelmaking plant: a hybrid material/energy flow analysis case study," Sustainable Energy Technologies and Assessments, vol. 2, no. 1, pp. 67-80, 2013.

[2] S. Zeng, Y. Lan, and J. Huang, "Mitigation paths for Chinese iron and steel industry to tackle global climate change," International Journal of Greenhouse Gas Control, vol. 3, no. 6, pp. 675-682, 2009.

[3] L. Chen, B. Yang, X. Shen et al., "Thermodynamic optimization opportunities for the recovery and utilization of residual energy and heat in China's iron and steel industry: a case study," Applied Thermal Engineering, vol. 86, pp. 151-160, 2015.

[4] Q. Chen, H. Shi, and M. Sun, "Echo state network-based backstepping adaptive iterative learning control for strictfeedback systems: an error-tracking approach," IEEE Transactions on Cybernetics, vol. 50, no. 7, pp. 3009-3022, 2019.

[5] L. Zhao, J. Yu, and H. Yu, "Barrier lyapunov functions-based command filtered output feedback control for full-state constrained nonlinear systems," Automatica, vol. 105, pp. 71-79, 2019.

[6] G. Cui, J. Yu, and Q. Wang, "Finite-time adaptive fuzzy control for MIMO nonlinear systems with input saturation via improved command filtered backstepping," IEEE Transactions on Systems, Man, and Cybernetics: Systems, 2020.

[7] C. Wang, C. Ryman, and J. Dahl, "Potential $\mathrm{CO}_{2}$ emission reduction for BF-BOF steelmaking based on optimised use of ferrous burden materials," International Journal of Greenhouse Gas Control, vol. 3, no. 1, pp. 29-38, 2009.

[8] S. Wang, J. Na, and Y. Xing, "Adaptive optimal parameter estimation and control of servo mechanisms: theory and experiments," IEEE Transactions on Industrial Electronics, 2020.

[9] J. Yu, P. Shi, and L. Zhao, "Finite-time command filtered backstepping control for a class of nonlinear systems," Automatica, vol. 92, pp. 173-180, 2018.

[10] Y. Li and L. Zhu, "Cost of energy saving and $\mathrm{CO}_{2}$ emissions reduction in China's iron and steel sector," Applied Energy, vol. 130, pp. 603-616, 2014.

[11] J. A. Moya and N. Pardo, "The potential for improvements in energy efficiency and $\mathrm{CO}_{2}$ emissions in the EU27 iron and steel industry under different payback periods," Journal of Cleaner Production, vol. 52, pp. 71-83, 2013.

[12] H. D. Baehr, "The exergy method of thermal plant analysis," Chemical Engineering and Processing: Process Intensification, vol. 21, no. 3, p. 163, 1987.

[13] J. Na, B. Wang, G. Li, S. Zhan, and W. He, "Nonlinear constrained optimal control of wave energy converters with adaptive dynamic programming," IEEE Transactions on Industrial Electronics, vol. 66, no. 10, pp. 7904-7915, 2019.

[14] S. Wang, L. Tao, Q. Chen, J. Na, and X. Ren, "Usde-based sliding mode control for servo mechanisms with unknown system dynamics," IEEE/ASME Transactions on Mechatronics, vol. 25, no. 2, pp. 1056-1066, 2020.

[15] C. Fu, Q. Wang, and J. Yu, "neural network-based finite-time command filtering control for switched nonlinear systems with backlash-like hysteresis," IEEE Transactions on Neural Networks and Learning Systems, 2020.

[16] J. Yu, P. Shi, C. Lin, and H. Yu, "Adaptive neural command filtering control for nonlinear MIMO systems with saturation input and unknown control direction," IEEE Transactions on Cybernetics, vol. 50, no. 6, pp. 2536-2545, 2020.

[17] T. Akiyama and J.-i. Yagi, "Exergy analysis of conventional ironmaking, direct reduction-electric furnace and smelting reduction systems," Tetsu-to-Hagane, vol. 74, no. 12, pp. 2270-2277, 1988. 
[18] H. nogami, J.-i. Yagi, and R. S. Sampaio, "Exergy analysis of charcoal charging operation of blast furnace," ISIJ International, vol. 44, no. 10, pp. 1646-1652, 2004.

[19] A. Ziebik and W. Stanek, "“'Influence of blast-furnace process thermal parameters on energy and exergy characteristics and exergy losses," International Journal of Energy Research, vol. 30, no. 4, pp. 203-219, 2006.

[20] A. Ziebik and W. Stanek, "“Energy and exergy system Analysis of thermal improvements of blast-furnace plants," International Journal of Energy Research, vol. 30, no. 2, pp. 101-114, 2006.

[21] W. Zhang, Exergy Analysis of Blast Furnace Process, Northeastern University, Shenyang, China, 2009.

[22] T. Guo, M. Chu, and Z. Liu, "Exergy analysis on blast furnace process with coke oven injection," Journal of Central South University Science Technology Vers, vol. 8, pp. 3108-3114, 2013.

[23] Z. Wang, Numerical Analysis and Optimization for Blast Furnace Process, University of Science and Technology Beijing, Beijing, China, 1992.

[24] J. Szargut, "Exergy balance of metallurgical processes," Psychonomic Bulletin \& Review, vol. 16, no. 2, pp. 276-281, 1961.

[25] U. Yildirim and A. Gungor, "An application of exergoeconomic analysis for a CHP system," International Journal of Electrical Power \& Energy Systems, vol. 42, no. 1, pp. 250-256, 2012.

[26] T. Blumberg, M. Assar, T. Morosuk, and G. Tsatsaronis, "Comparative exergoeconomic evaluation of the latest generation of combined-cycle power plants," Energy Conversion and Management, vol. 153, pp. 616-626, 2017.

[27] C. Uysal, H. Kurt, and H.-Y. Kwak, "Exergetic and thermoeconomic analyses of a coal-fired power plant," International Journal of Thermal Sciences, vol. 117, pp. 106-120, 2017.

[28] X. Wang, Y. Yang, Y. Zheng, and Y. Dai, "Exergy and exergoeconomic analyses of a supercritical $\mathrm{CO}_{2}$ cycle for a cogeneration application," Energy, vol. 119, pp. 971-982, 2017.

[29] H. Holmberg, M. Tuomaala, T. Haikonen, and P. Ahtila, "Allocation of fuel costs and $\mathrm{CO}_{2}$-emissions to heat and power in an industrial CHP plant: case integrated pulp and paper mill," Applied Energy, vol. 93, pp. 614-623, 2012.

[30] R. G. dos Santos, P. R. de Faria, J. J. C. S. Santos, J. A. M. da Silva, and D. Flórez-Orrego, "Thermoeconomic modeling for $\mathrm{CO}_{2}$ allocation in steam and gas turbine cogeneration systems," Energy, vol. 117, pp. 590-603, 2016.

[31] J.-J. Cai, H. Dong, T. Du et al., "Study on grade recovery and cascade utilization of waste heat from sintering-cooling process," Kang T'ieh/Iron and Steel (Peking), vol. 46, no. 4, pp. 88-92, 2011.

[32] M. Arens, E. Worrell, and J. Schleich, "Energy intensity development of the German iron and steel industry between 1991 and 2007," Energy, vol. 45, no. 1, pp. 786-797, 2012.

[33] B. Erlach, L. Serra, and A. Valero, "Structural theory as standard for thermoeconomics," Energy Conversion and Management, vol. 40, no. 15-16, pp. 1627-1649, 1999.

[34] A. Lazzaretto and G. Tsatsaronis, "SPECO: a systematic and general methodology for calculating efficiencies and costs in thermal systems," Energy (Oxford), vol. 31, no. 8-9, pp. 1257-1289, 2006.

[35] S. Li, Research on Energy Efficiency Assessment Method of Iron and Steel Production Process Based on Exergy Analysis, Shandong University, Jinan, China, 2013.

[36] H. Caliskan, "Novel approaches to exergy and economy based enhanced environmental analyses for energy systems," Energy Conversion and Management, vol. 89, pp. 156-161, 2015. 